\title{
PEAK EXPIRATORY FLOW AS A SURROGATE FOR HEALTH RELAT- ED QUALITY OF LIFE IN CHRONIC OBSTRUCTIVE PULMONARY DISEASE: A PRELIMINARY CROSS SECTIONAL STUDY
}

\author{
D.O. OBASEKI ${ }^{1}$, M.O. AKANBI ${ }^{2}$, C.C. ONYEDUM ${ }^{3}$, O.B. OZOH $^{4}$ J. JUMBO $^{5}$, A.A. AKOR ${ }^{6}$ and \\ G.E. ERHABOR ${ }^{1}$ \\ ${ }^{1}$ Department of Medicine, Obafemi Awolowo University, Ile-Ife, Nigeria, ${ }^{2}$ Department of Medicine, Universi- \\ ty of Jos, Jos, Nigeria, $\quad{ }^{3}$ Department of Medicine, University of Nigeria, Enugu Campus, Nigeria, \\ ${ }^{4}$ Department of Medicine, University of Lagos, Lagos, Nigeria, ${ }^{5}$ Department of Medicine, Niger Delta Univer- \\ sity, Wilberforce Island, Bayelsa State, Nigeria, ${ }^{6}$ Department of Medicine, University of Abuja Teaching \\ Hospital, Gwagwalada, Abuja, Nigeria
}

DOI: http://dx.doi.org/10.4314/gmj.v48i2.5

Corresponding Author: Dr. Daniel O Obaseki

Email:_danseki@yahoo.com

Conflict of Interest: None declared

\section{SUMMARY}

Background: Health Related Quality of Life (HRQL) measures can capture the non-respiratory effects of Chronic Obstructive Pulmonary Disease (COPD). However the relationship with Peak Expiratory Flow (PEF) is not well understood

Aim: To determine the relationship of PEF and quality of life measurements in patients with COPD

Settings and Design: A cross section of consecutive patients in a university clinic

Methods: Stable patients with COPD defined by the Global Initiative on chronic Obstructive Lung Disease (GOLD) criteria, were recruited into the study. Spirometry was done using American Thoracic Society's standards and reference equations from African American norms of the US population. Quality of life was measured with the St George's Respiratory Questionnaire (SGRQ)

Results: Out of 50 patients recruited for the study, 48 provided complete data with acceptable spirometry and PEF data. The mean (SD) age and body mass index was $68.4(8.9)$ years and $21.4(4.6) \mathrm{kg} / \mathrm{m}^{2}$ respectively and $96 \%$ of the patients were in moderate-severe stages of COPD using the GOLD criteria. Percent predicted PEF correlated with percent predicted FEV1; $r=0.559$ $\mathrm{p}<0.001$ and also showed a significant, though moderate correlation between PEF readings and SGRQ scores especially in the activity $(\mathrm{r}=-0.455 \mathrm{p}<0.01)$ and total scores $(r=-0.415 p<0.01)$ for pre bronchodilator $(B D)$ percent predicted PEF. In regression analysis, PEF was associated with SGRQ $(-0.1195 \%$ CI $-0.19,-0.03)$ after adjusting for age, sex, height, smoking and disease severity

Conclusions: PEF correlates with SGRQ scores and may be a useful surrogate for HRQL in patients with COPD
Key words: Peak expiratory flow, quality of life, spirometry, primary care

\section{INTRODUCTION}

Chronic Obstructive Pulmonary Disease (COPD) is a respiratory disorder of significant public health importance. It is presently ranked as the third most important cause of death worldwide. ${ }^{1}$ A diagnosis of COPD is established by a post bronchodilator (BD) forced expiratory volume in the first second (FEV1)/forced vital capacity (FVC) ratio of less than $0.7^{2}$ or the lower limit of normal (LLN). ${ }^{3}$ It is largely under diagnosed in developing countries for various reasons including lack of affordable spirometers in primary care settings. ${ }^{4}$

Though the peak flow meter have been dismissed as unreliable for diagnosing COPD, ${ }^{5,6}$ recent reports suggests that peak flow measurements may be an inexpensive way of screening ${ }^{7}$ and initial identification of severe cases of COPD for subsequent confirmatory spirometry. ${ }^{8,9}$ However COPD is a multi-systemic disease with extra-pulmonary manifestations that often elude spirometric assessment. ${ }^{10,11}$

Quality of life is an important criterion in the assessment of the impact and treatment outcome in patients with COPD. Quality of life scores assess an individual's ability to perform and derive satisfaction from activities of daily living such as social role functioning, home management, social and family relationships, self-care, mobility, recreation and hobbies. ${ }^{12}$ 
Quality of life questionnaires are commonly used to capture the non-respiratory manifestations of COPD but they are often difficult to complete in busy clinics especially in low literacy settings as in many developing countries. Peak flow meters could potentially serve as tools both for screening and for providing a measure of health related quality of life in COPD. It is thus imperative to understand how measures of peak expiratory flow (PEF) relate with quality of life scores.

We undertook a cross sectional assessment of patients with COPD to determine the relationship between PEF and quality of life measurements using the St George's Respiratory Questionnaire (SGRQ).

\section{METHODS}

\section{Study Design}

It was a cross sectional study. Stable patients with COPD were recruited consecutively from the outpatient respiratory clinic of Obafemi Awolowo University (OAU) teaching hospital, Ile-Ife, Nigeria. Inclusion criteria included a previous diagnosis of COPD based on a post bronchodilator FEV1/FVC ratio below 0.7 . Patients were also further categorized into stages of disease severity using the criteria defined by the Global initiative for chronic Obstructive Lung Disease (GOLD). ${ }^{2}$

Patients were judged as stable if there was no history of recent worsening of symptoms, hospitalization or change in their medications over the preceding six weeks before presentation in the clinic.

\section{Measurements \\ Health Status}

Health related quality of life (HRQL) was assessed using the St George's Respiratory Questionnaire (SGRQ). ${ }^{13}$ The SGRQ is a weighted questionnaire that has been shown to be valid, reliable and reproducible in patients with COPD. It contains 50 items with 76 weighted responses that cover three domains: symptoms - distress due to respiratory symptoms, activity disturbances of physical activity and impact - overall impact on daily life and well-being.

In addition to the domain scores, there is also a total score. ${ }^{14}$ The SGRQ is scaled from zero to 100 (with zero representing the best health-related quality of life). This questionnaire, which was forward and back translated in Yoruba language, was administered to each participant face to face by a trained interviewer.

\section{Lung function}

The FEV1 and FVC were measured using a standardized bellows spirometer (Vitalograph Ltd, Buckingham, England. 1997, Model 2150).
The PEF was measured using the mini-Wright peak flow meter. ${ }^{15,16}$ The parameters were assessed before and 20 minutes after the inhalation of $400 \mu \mathrm{g}$ of Salbutamol using a metered dose inhaler (MDI) and a spacer device. For spirometry, a minimum of three and a maximum of eight spirometry maneuvers were done according to ERS/ATS criteria. ${ }^{17}$ The best three acceptable and reproducible maneuvers (within 200ml) were recorded for each patient.

For measurement of peak expiratory flow, patients were instructed to inhale to total lung capacity and exhale with a forceful blast. Three measurements were made and the best was recorded. The reference equation for the spirometry and PEF was derived from the African American norms of the third National Health and Nutrition Examination Survey (NHANES III). ${ }^{18}$

\section{Other measurements}

Height was measured without shoes to the nearest centimeter using a wall-mounted stadiometer while weight was measured without outer garment to the nearest 0.1 kilogram using a portable weight scale after zero calibration check.

\section{Data analysis}

The data was analyzed using Stata 11.2 statistical package (Stata Corp., College Station, TX, USA). ${ }^{19}$ Continuous data were presented as means and standard deviations while categorical and discrete data were presented using proportions and frequencies. The SGRQ data was analyzed using the excel-based weighted scoring calculator developed in St George's Hospital.

Correlation coefficients between peak expiratory flow and the domains scores of the SGRQ was determined using spearman's correlation. Multiple linear regressions was used to determine the independent effect of PEF on SGRQ quality of life total scores after adjusting for the following co-variates- age, sex, height, smoking status and GOLD classification of disease severity. The best model was determined by changes in $\mathrm{R}$ squared value.

\section{Ethical Clearance}

The study protocol was approved by the ethics committee of Obafemi Awolowo University teaching hospital. Informed written consent was obtained from each study participant.

\section{RESULTS}

Out of 50 patients recruited for the study, 48 provided complete data with acceptable spirometry and PEF data and were included in the analysis. 
The general characteristics of the patients included in the final analysis are shown in Table 1.

Forty percent of the respondents were female. The mean (SD) age and body mass index of the study population was $68.4(8.9)$ years and $21.4(4.6) \mathrm{kg} / \mathrm{m}^{2}$ respectively. Fifty two percent of the patients had never smoked cigarette and almost all (96\%) of the patients were at least in moderate-severe stages of COPD using the GOLD criteria.

Table 1 Characteristics of the study participants

\begin{tabular}{|l|l|}
\hline Variable & Mean \pm SD or n (\%) \\
\hline Age (years) & $68.4 \pm 8.9$ \\
\hline Height $(\mathrm{cm})$ & $161.9 \pm 8.9$ \\
\hline BMI $(\mathrm{Kg} / \mathrm{m} 2)$ & $21.4 \pm 4.6$ \\
\hline Smoking Status & \\
\hline Never & $25(52)$ \\
\hline Previous & $23(48)$ \\
\hline Current & - \\
\hline GOLD Classification & \\
\hline Mild & $2(4)$ \\
\hline Moderate & $12(25)$ \\
\hline Severe & $20(42)$ \\
\hline Very Severe & $14(29)$ \\
\hline
\end{tabular}

SD - Standard Deviation; BMI - Body Mass Index; GOLD- Global initiative for chronic Obstructive Lung Disease

Post bronchodilator FEV1/FVC $<0.7$ \& FEV1 $\geq 80 \%$ predicted

(Mild); $50 \%<=$ FEV1 $<80 \%$ predicted (Moderate); $30 \%<=$ FEV1 $<$

$50 \%$ predicted (Severe); FEV $1<30 \%$ predicted (Very Severe).

Proportions reported are based on the entire sample of patients.

Sixty five percent of the patients had peak flow readings below the acceptable lower limit of normal (LLN) for their age and height (Table 2). The mean (SD) of predicted post bronchodilator (post BD) PEF, FEV1, FVC and FEV1/FVC were $67.5 \%$ (30.7), $40.7 \%$ (17.4), 59.9\% (26.1) and $67.7 \%$ (14.1) respectively.

In addition, there was a significant, though moderate correlation between PEF readings and SGRQ scores (Table 3). However the correlation between FEV1 and SGRQ scores were weak and generally not significant (Data not shown). The correlation between PEF and SGRQ was best in the activity and total scores.

The coefficients in the SGRQ activity score were $\mathrm{r}=$ $0.453 \mathrm{p}<0.01$ (pre BD PEF (1/min)), $r=-0.455 \mathrm{p}<0.01$ (pre BD \% PEF), $r=-0.469 \mathrm{p}<0.001 \quad$ (post BD PEF $(1 / \mathrm{min})$ ) and $\mathrm{r}=-0.450 \mathrm{p}<0.01$ (post $\mathrm{BD} \% \mathrm{PEF}$ ). The coefficients for the total scores were $\mathrm{r}=-0.370 \mathrm{p}<0.01$, $\mathrm{r}=-0.415 \mathrm{p}<0.01, \mathrm{r}=-0.435 \mathrm{p}<0.01$ and $\mathrm{r}=-0.431 \mathrm{p}<0.01$ for pre $\mathrm{BD} \mathrm{PEF} 1 / \mathrm{min}$, pre $\mathrm{BD} \% \mathrm{PEF}$, post $\mathrm{BD} \mathrm{PEF}$ $1 /$ min and post $\mathrm{BD} \% \mathrm{PEF}$ respectively.
Peak expiratory flow was associated with SGRQ (-0.11 $95 \%$ CI $-0.19,-0.03)$ after adjusting for age, sex, height, smoking status and GOLD classification of severity (Table 4). This model explained $17 \%$ of the variability in SGRQ total score.

Table 2 Lung function and SGRQ scores of the participants

\begin{tabular}{|c|c|}
\hline Variable & $\begin{array}{l}\text { Mean } \pm \text { SD or } \\
\%(\mathrm{SE})\end{array}$ \\
\hline Pre BD PEF L/min & $217.0 \pm 91.2$ \\
\hline Post BD PEF L/min & $235.4 \pm 100.6$ \\
\hline Pre BD PEF (\% Predicted) & $62.2 \pm 27.7$ \\
\hline Post BD PEF (\% Predicted) & $67.5 \pm 30.7$ \\
\hline Pre BD FEV1 (L) & $0.8 \pm 0.4$ \\
\hline Post BD FEV1 (L) & $0.8 \pm 0.4$ \\
\hline Pre BD FEV1 (\% Predicted) & $39.7 \pm 18.4$ \\
\hline Post BD FEV1 (\% Predicted) & $40.7 \pm 17.4$ \\
\hline Pre BD FVC (L) & $1.5 \pm 0.6$ \\
\hline Post BD FVC (L) & $1.6 \pm 0.6$ \\
\hline Pre BD FVC (\% Predicted $)$ & $57.5 \pm 23.0$ \\
\hline Post BD FVC (\% Predicted $)$ & $59.9 \pm 26.1$ \\
\hline Pre BD FEV1/FVC (\%) & $52.2 \pm 10.9$ \\
\hline Post BD FEV1/FVC (\%) & $52.3 \pm 11.3$ \\
\hline Pre BD FEV1/FVC (\% Predicted) & $67.5 \pm 13.6$ \\
\hline Post BD FEV1/FVC (\% Predicted) & $67.7 \pm 14.1$ \\
\hline Post BD PEF $<$ LLN * & $64.6(6.9)$ \\
\hline Post BD FEV1 <LLN* & $93.8(3.5)$ \\
\hline Post BD FVC $<\mathrm{LLN}^{*}$ & $81.3(5.6)$ \\
\hline Post BD FEV1/FVC $<\mathrm{LLN}^{*}$ & $91.6(4.0)$ \\
\hline SGRQ - Symptom & $45.4 \pm 26.9$ \\
\hline SGRQ - Activity & $49.3 \pm 29.1$ \\
\hline SGRQ - Impact & $29.1 \pm 19.9$ \\
\hline SGRQ - Total & $38.0 \pm 22.1$ \\
\hline
\end{tabular}

Standard Deviation, SE - Standard Error, SGRQ - St George's Respiratory Questionnaire, BD - Bronchodilator, FEV1 - Forced expiratory volume in one second, FVC- Forced Vital Capacity, PEF - Peak Expiratory Flow, LLN - Lower Limit of Normal

*Represents proportions below the LLN and standard error based on prediction values derived from equations for African Americans in the third National Health and Nutrition Examination Survey (NHANES)

\section{DISCUSSION}

Our study showed that PEFR correlates with SGRQ quality of life scores in patients with COPD but explains a small proportion of the variance in quality of life after adjusting for age, sex, height, smoking status and disease severity. We also found that $64 \%$ of the patients had peak flow readings below the lower limit of normal for their age and height. 
Our study provides preliminary data on the relationship between PEF and quality of life in patients with COPD, suggesting its possible utility as a surrogate for assessing quality of life in patients with COPD.

Table 3. Correlation coefficients between PEF, FEV1, FVC and SGRQ scores ${ }^{8}$

\begin{tabular}{|c|c|c|c|c|c|c|c|c|c|c|}
\hline \multirow[b]{2}{*}{ PEF } & \multicolumn{4}{|c|}{ SGRQ } & \multicolumn{4}{|c|}{ FEV1 } & \multicolumn{2}{|c|}{ FVC } \\
\hline & Symptom & Activity & Impact & Total & $\begin{array}{l}\text { Pre FEV1 } \\
\text { (L) }\end{array}$ & $\begin{array}{l}\text { Pre FEV1 } \\
(\% \text { Pred })\end{array}$ & $\begin{array}{l}\text { Post FEV1 } \\
\text { (L) }\end{array}$ & $\begin{array}{l}\text { Post FEV1 } \\
\text { (\% Pred) }\end{array}$ & $\begin{array}{l}\text { Pre FVC } \\
(\% \text { Pred })\end{array}$ & $\begin{array}{l}\text { Post FVC } \\
\text { (\% Pred) }\end{array}$ \\
\hline $\begin{array}{l}\text { Pre BD PEF } \\
(\mathrm{L} / \mathrm{min})\end{array}$ & $-0.394 * *$ & $-0.453 * *$ & -0.281 & $-0.370 * *$ & $0.649^{* * *}$ & $0.489 * * *$ & $0.591^{* * *}$ & $0.407^{* * *}$ & $0.394^{* *}$ & 0.242 \\
\hline $\begin{array}{l}\text { Pre BD PEF ( } \% \\
\text { Predicted) }\end{array}$ & $-0.394 * *$ & $-0.455 * *$ & $-0.353 *$ & $-0.415^{* *}$ & $0.368^{*}$ & $0.559 * * *$ & $0.308^{*}$ & $0.505^{* * *}$ & $0.432 * *$ & $0.321^{*}$ \\
\hline $\begin{array}{l}\text { Post BD PEF } \\
(\mathrm{L} / \mathrm{min})\end{array}$ & $-0.385^{* *}$ & $-0.469 * * *$ & $-0.372 * *$ & $-0.435^{* *}$ & $0.686^{* * *}$ & $0.556^{* * *}$ & $0.633^{* * *}$ & $0.479^{* * *}$ & $0.417^{* *}$ & $0.293^{*}$ \\
\hline $\begin{array}{l}\text { Post BD PEF }(\% \\
\text { Predicted })\end{array}$ & $-0.344 *$ & $-0.450 * *$ & $-0.431^{* *}$ & $-0.458 * *$ & $0.417^{* *}$ & $0.661^{* * *}$ & $0.372^{* *}$ & $0.612^{* * *}$ & $0.518^{* * *}$ & $0.432^{* *}$ \\
\hline
\end{tabular}

SGRQ - St George's Respiratory Questionnaire, PEF - Peak Expiratory Flow, BD - Bronchodilator, FEV1 - Forced expiratory volume in one second, FVC- Forced Vital Capacity. Pred- Predicted

SGRQ is divided into three subscores; 'symptom', 'activity', 'impact' and a 'total' score

'Pre' represents pre-bronchodilator test results while 'post' represents post-bronchodilator test results using salbutamol as a bronchodilating agent.

$\S$ - Spearman's correlation coefficients

$* \mathrm{p}<0.05 * * \mathrm{p}<0.01 * * * \mathrm{p}<0.001$

Table 4 Multiple regression analysis of SGRQ total scores and peak expiratory flow rates

\begin{tabular}{lcccccccccc}
\hline \multicolumn{1}{c}{ SGRQ Total } & Coefficient & SE & \multicolumn{3}{c}{$95 \%$ CI } & P value & Coefficient & SE & \multicolumn{3}{c}{ A5\% CI } & P value \\
\hline & & \multicolumn{3}{c}{ Unadjusted } & & & & \\
Age & 0.16 & 0.35 & -0.55 & 0.87 & 0.66 & 0.15 & 0.34 & -0.54 & 0.84 & 0.66 \\
Sex & -6.99 & 6.34 & -19.74 & 5.77 & 0.28 & -12.57 & 9.86 & -32.50 & 7.35 & 0.21 \\
Height (cm) & 0.03 & 0.36 & -0.69 & 0.75 & 0.93 & 0.81 & 0.44 & -0.07 & 1.69 & 0.07 \\
Smoking Status & -2.27 & 6.30 & -14.95 & 10.40 & 0.72 & 3.95 & 8.00 & -12.20 & 20.11 & 0.62 \\
GOLD Classification & 6.94 & 3.57 & -0.24 & 14.12 & 0.06 & 0.27 & 4.03 & -7.87 & 8.40 & 0.95 \\
Pre BD PEF & $\mathbf{- 0 . 1 1}$ & $\mathbf{0 . 0 3}$ & $\mathbf{- 0 . 1 7}$ & $\mathbf{- 0 . 0 5}$ & $\mathbf{0 . 0 0}$ & $\mathbf{- 0 . 1 1}$ & $\mathbf{0 . 0 4}$ & $\mathbf{- 0 . 1 9}$ & $\mathbf{- 0 . 0 3}$ & $\mathbf{0 . 0 1}$ \\
Intercept & & & & & & -65.74 & 68.22 & -203.51 & 72.03 & 0.34 \\
\hline
\end{tabular}

SGRQ - St George's Respiratory Questionnaire, PEF - Peak Expiratory Flow, SE - Standard Error, CI - Confidence Interval

Adjusted coefficient of determination $(\mathrm{R} 2)=17 \%$

We found strong correlation between PEF and FEV1 readings, moderate correlation between $\mathrm{PEF}$ and SGRQ but weak correlation between SGRQ and FEV1.

In a previous analysis, ${ }^{20}$ we noted that the correlation between SGRQ scores and lung function parameters like FEV1 and FVC was weak, possibly suggesting that spirometry and quality of life are independent, albeit complementary modalities of evaluation of patients with COPD. PEF correlates with FEV1 but unlike FEV1, PEF also correlate with SGRQ quality of life scores (Table 3).

The relationship between PEF and quality of life in patients with COPD is possibly connected to daily changes in respiratory airflow capacity, ventilatory ability and sense of breathlessness, which impacts significantly on quality of life.

Though the diagnosis of COPD is spirometry-based, ${ }^{2}$ it is worthwhile to note that there is no evidence to suggest that spirometry has an advantage over PEF in the day-to-day monitoring or management of patients with COPD,${ }^{21}$ neither is it time efficient or easier to perform. $^{22}$

As a result, PEF measurements, even without bronchodilation, could provide useful and readily accessible information to the general practitioner or primary care physicians about the daily or short-term structural changes in the airway and its effect on quality of life. 
We also observed that pre bronchodilator PEF predicts SGRQ quality of life score independent of age, sex, height, smoking status or severity of COPD. However, PEF explains a small percentage of the variability in SGRQ scores and as such, there may be other parameters that also affect quality of life in COPD other than a simple measurement of the airflow status using a PEF meter.

There is very sparse information on the utility of PEF assessment as an outcome measure in COPD. Hansen and colleagues showed that PEF could be used to predict survival in patients with COPD. ${ }^{23}$ They compared the utility of FEV1 and PEF for assessing outcome in a sample of 1095 patients with COPD who were initially enrolled in the Copenhagen City Study. ${ }^{23}$ After a decade of follow up, they found the best PEF was at least equal to the best FEV1 as a predictor of overall mortality in subjects with COPD, after controlling for age, smoking, sex, and body mass index. They concluded that, “.... despite close correlation to FEV1, PEF provided independent prognostic information in patients with COPD". ${ }^{23}$ The present study corroborates this finding and indicates that PEF may thus be invaluable in assessing the impact of COPD and for predicting its long-term outcome especially in primary care centres. However, there is clearly a need for large sensitivity studies on this subject.

Interestingly, we also observed that sixty five percent of the patients in our study population had low lung function parameters (FEV1 \& FVC) compared with predicted values using reference equations for African Americans. Forced vital capacity has been shown to correlate with survival. ${ }^{24}$ Populations with low forced vital capacity appear to suffer greater mortality however its determinants are poorly understood. Our population of patients was generally of the low socioeconomic class, a group known to have poor access to health care. It is unclear why our sample of patients had very low forced vital capacity and other lung parameters. This may probably be because the patients with COPD in our clinics appears quite late for treatment when they are already at advanced stages of the disease. Low lung function parameters may also suggest low maximally attained pre-morbid lung function and a subsequent rapid decline over time, a phenomenon described as 'horse racing'. ${ }^{25,} 26$ Though this phenomenon cannot be evaluated in the present cross sectional study, it warrants further investigation.

It is important, however, to exercise caution in interpreting the results of the present study. Our sample comprised patients with moderate-severe cases of COPD and the results may not be applicable to all cases of COPD. Our PEF measurements were obtained separately from spirometry test using mini-Wright peak flow meters. This may not be entirely comparable with PEF readings obtained from spirometry manoevres as was done is previous studies. ${ }^{8,9}$ In addition, this study is limited by the small sample size. A larger study will provide more robust effect estimates.

Notwithstanding these limitations, this study adds to the body of evidence that shows that PEF meters may be veritable tools for evaluating patients especially in clinic settings. It also provides a simple measure of the expiratory flow and large airway caliber.

It is important for policy makers to encourage further research into the applicability of this simple and inexpensive device as a screening tool in COPD and as a marker of HRQL. This by no means suggests that spirometry should be replaced by PEF in the evaluation of ventilation but rather, in local clinics with no access to quality spirometry, a measure of PEF in patients with severe COPD can provide a reasonably good day-today indication of the lung function and quality of life status.

\section{CONCLUSION}

In conclusion we have shown that peak expiratory flow correlates with quality of life scores and may be an important simple measure for assessing both lung function and quality of life in patients with COPD in lowincome primary care settings.

\section{ACKNOWLEDGEMENT:}

We wish to express our gratitude to all the patients who participated in this study

\section{REFERENCES}

1. Lozano R, Naghavi M, Foreman $\mathrm{K}$, Lim $\mathrm{S}$, Shibuya K, Aboyans V, et al. Global and regional mortality from 235 causes of death for 20 age groups in 1990 and 2010: A systematic analysis for the global burden of disease study 2010. The Lancet. 2013; 380(9859): 2095-128.

2. GOLD - the global initiative for chronic obstructive lung disease; cited 5/29/2013. Available from: http://www.goldcopd.org/guidelines-globalstrategy-for-diagnosis-management.html.

3. Swanney MP, Ruppel G, Enright PL, Pedersen OF, Crapo RO, Miller MR, et al. Using the lower limit of normal for the FEV1/FVC ratio reduces the misclassification of airway obstruction. $\mathrm{Br}$ Med J. 2008; 63 (12): 1046-51

4. Salvi SS, Barnes PJ. Chronic obstructive pulmonary disease in non-smokers. Lancet (London, England). 2009; 374 (9691): 733-43. 
5. Thiadens H, De Bock G, Van Houwelingen J, Dekker F, De Waal M, Springer M, et al. Can peak expiratory flow measurements reliably identify the presence of airway obstruction and bronchodilator response as assessed by FEV1 in primary care patients presenting with a persistent cough? Thorax. 1999; 54 (12): 1055-60.

6. Kelly C, Gibson G. Relation between FEV1 and peak expiratory flow in patients with chronic airflow obstruction. Thorax. 1988; 43(4): 335-6.

7. Jackson H, Hubbard R. Detecting chronic obstructive pulmonary disease using peak flow rate: Cross sectional survey. BMJ. 2003; 327(7416): 653-4.

8. Jithoo A, Enright PL, Burney P, Buist AS, Bateman ED, Tan WC, et al. Case-finding options for COPD: Results from the burden of obstructive lung disease study. Eur Respir J. 2013; 41 (3): 548-55.

9. Perez-Padilla R, Vollmer W, Vázquez-García J, Enright P, Menezes A, Buist A. Can a normal peak expiratory flow exclude severe chronic obstructive pulmonary disease? Int J Tuberc Lung Dis. 2009; 13 (3): 387.

10. Jones PW. Issues concerning health-related quality of life in COPD. Chest-Supplements. 1995; 107 (5): $187 \mathrm{~S}$.

11. Jones P. Health status measurement in chronic obstructive pulmonary disease. Thorax. 2001;56 (11):880-7.

12. Hütter B, Würtemberger G. [Functional capacity (dyspnea) and quality of life in patients with chronic obstructive lung disease (COPD): Instruments of assessment and methodological aspects]. Pneumologie. 1999; 53 (3): 133-42.

13. Jones PW, Quirk FH, Baveystock CM, Littlejohns P. A self-complete measure of health status for chronic airflow limitation. The St. George's Respiratory Questionnaire. Am Rev Respir Dis. 1992; 145 (6): 1321-7.

14. Jones PW, Quirk F, Baveystock C. The St George's Respiratory Questionnaire. Respir Med. $1991 ; 85: 25-31$.
15. Perks W, Tams I, Thompson D, Prowse K. An evaluation of the mini-wright peak flow meter. Thorax. 1979; 34 (1): 79-81.

16. Wright B, McKerrow C. Maximum forced expiratory flow rate as a measure of ventilatory capacity. Br Med J. 1959; 2(5159): 1041.

17. Miller MR, Hankinson J, Brusasco V, Burgos F, Casaburi R, Coates A, et al. Standardisation of spirometry. Eur Respir J. 2005; 26(2): 319-38.

18. Hankinson JL, Odencrantz JR, Fedan KB. Spirometric reference values from a sample of the general US population. Am J Respir Crit Care Med. 1999; 159 (1): 179-87.

19. StataCorp L. Stata version 11.0. College Station, TX: StataCorp LP. 2009.

20. Obaseki D, Erhabor G, Awopeju O, Obaseki J, Adewole O. Determinants of Health Related quality of life in a sample of patients with chronic obstructive pulmonary disease in Nigeria using the St. George's Respiratory Questionnaire. Afr Health Sci 2013; 13(3): 694-702.

21. White P. Spirometry and peak expiratory flow in the primary care management of COPD. Pri Care Respir J 2004; 13(1):5-8.

22. Bush A, Cramer D. Guidelines for the measurement of respiratory function. Respir Med. 1994; 88(10): 798.

23. Hansen EF, Vestbo J, Phanareth K, Kok-Jensen A, Dirksen A. Peak flow as predictor of overall mortality in asthma and chronic obstructive pulmonary disease. Am J Respir Crit Care Med.. 2001; 163(3): 690-3.

24. Burney P, Hooper R. Forced vital capacity, airway obstruction and survival in a general population sample from the USA. Thorax. 2011; 66(1): 49-54.

25. Peto R. The horse-racing effect. The Lancet. 1981; 318 (8244): 467-8.

26. Burrows B, Knudson RJ, Camilli AE, Lyle SK, Lebowitz MD. The" horse-racing effect" and predicting decline in forced expiratory volume in one second from screening spirometry. Am Rev Respir Dis. 1987; 135 (4): 788-93. 